
\title{
$\begin{array}{ll}\text { Research Square } & \begin{array}{l}\text { They should not be considered conclusive, used to inform clinical practice, } \\ \text { or referenced by the media as validated information. }\end{array}\end{array}$
}

\section{Evaluation of One-Year Antibiotics Utilization in the Adult Outpatient Pharmacy of a Nigerian Tertiary Health Institution}

Angus N. OLI

Department of Pharmaceutical Microbiology and Biotechnology, Nnamdi Azikiwe University, Awka, Nigeria

Nwanneka ONYEASO

Department of Clinical Pharmacy and Pharmacy Practice, University of Benin, Nigeria.

Stephen Chijioke Emencheta ( $\nabla$ stephen.emencheta@unn.edu.ng )

University of Nigeria https://orcid.org/0000-0002-9579-7029

Chijioke M. OFOMATA

Department of Clinical Pharmacy and Pharmacy Management, Nnamdi Azikiwe University

James-Paul KRETCHY

Department of Physician Assitantchip Studies, School of Medicine and Health Sciences, Central University, Accra, Ghana

Augustine OKHAMAFE

Department of Pharmaceutics, Faculty of Pharmacy, University of Benin, Nigeria

\section{Research}

Keywords: Pharmacy Practice, Antibiotics use, Rational Prescribing, Essential Drug List, Drug Utilization

Posted Date: July 6th, 2020

DOI: https://doi.org/10.21203/rs.3.rs-39390/v1

License: (c) (1) This work is licensed under a Creative Commons Attribution 4.0 International License. Read Full License 


\section{Abstract}

Background: Antibiotics are among the most common drugs used worldwide. They kill or prevent the growth of bacterial microorganisms in the body, hence, they are the major agents used in treating bacterial infections. Because they are prone to abuse and misuse, regular evaluation of their utilization is important for optimal healthcare delivery.

Objective: This study determined the antibiotics type, utilization, prescriptions and cost patterns in the adult out-patient pharmacy of a public tertiary health facility in Nigeria.

Methods: This is a retrospective observational study using medication utilization records (prescriptions) to investigate the study objectives. Prescriptions dispensed in 2018 in adult out-patient pharmacy of Nnamdi Azikiwe University Teaching Hospital, Nnewi were reviewed. Data were evaluated using the World Health Organization-developed prescribing indicators. Descriptive and inferential statistics were used to analyze the results. The percentage and averages of the variable were calculated.

Results: The medication utilization records showed that there was a significantly higher proportion (P-value $=0.0038)$ of females $(70 \%)$ compared to males (the ratio being 2.44:1.00) that were prescribed antibiotics. The antibiotic utilization profile showed that antibiotic selection by class was significantly different and accounted for $44.02 \%$ of the total variance seen in the prescription pattern (P-value is $<0.0001$ ). Also, the age of participants accounted for $19.48 \%$ of the total variance seen in the selection practice and so, age significantly affected the selection practice/prescription pattern with P-value $<0.0001$. Dosage forms profile showed that the oral dosage forms were significantly more prescribed ( $P$-value $<0.0001$ ) compared with any other dosage form encountered in the study. There was no significant difference in the prescription patterns of parenteral and other dosage forms $(P$-value $>0.05)$. A greater percentage $(84.22 \%)$ of the prescriptions was from the Essential Drug list of Nigeria.

Conclusion: Though the percentage of antibiotics prescribed from essential medicines list was found to be satisfactory, a strict protocol for prescribers is required to promote rational antibiotics use. This would not only prevent antibiotic resistance but also reduce the treatment expenditure and encourage antibiotic stewardship.

\section{Introduction}

The challenges of irrational prescribing, poly-pharmacy, use of "off-label" drugs including antibiotics with improper efficacy are creating enormous public health problems globally and in developing countries in particular [1,2,3]. Antibiotics are medications that can destroy or inhibit the growth of bacteria by either selectively killing or inhibiting the development of disease-causing bacteria [4]. They play a pivotal role in combating disease and maintaining health especially in developing countries where infectious diseases are still a big challenge [4]. The World Health Organization (WHO) stated that more than $50 \%$ of all drugs are irrationally prescribed or dispensed and also more than $50 \%$ of the patients have adherence problems with the prescribed regimens [5]. The improper utilization of these antibiotics is often caused by medical practitioners prescribing antibiotics for diagnosis that do not require antibiotic treatment, patients' request, and the empirical use of antibiotics as the main way of treating infections [6].

Regular and timely evaluation of antibiotic utilization and continuous epidemiological monitoring [7] are the watch-dog to mitigate or eliminate the above vices that militate against the gains of healthcare delivery and will aid evidence-based decision for limiting the spread and controlling bacterial infections [7]. Drug utilization, generally, has been defined as the marketing, distribution, prescription and use of drugs in a society with special emphasis on the resulting medical and social consequences [8]. Some of the benefits of proper healthcare delivery are the safety and effectiveness of prescribed drugs and affordability by the average person in the country. The inappropriate and overuse of antibiotics are examples of common types of irrational use which could lead to poor treatment outcomes, drug-drug interactions, and high economic burden on patients [9]. It is also one of the leading causes of microbial resistance observed to most antibiotics. Antibiotic resistance is a global health crisis and is one of the greatest challenges for public health and affects both developing and developed countries [4].

Developing countries have limited funds available for health care and drugs [9]. Also, stocking of quality medications from approved and legitimate sources is one of the principal safeguards against fake and substandard drugs [10]. Thus, it becomes very important to prescribe drugs, including antibiotics, rationally so that the available funds can be utilized optimally [7], while maintaining the safety and efficacy of the drugs. Therefore, the objectives of this study were to evaluate the demographic characteristics of patients in the adult out-patient pharmacy of Nnamdi Azikiwe University Teaching Hospital (NAUTH), Nnewi, describe the antibiotics use pattern, determine the antibiotics prescriptions per encounter, determine if prescribed antibiotics are on essential drug list and determined the cost associated with antibiotics use in the study site. Previous studies in NAUTH [11, 12], evaluated drug use in children in out-patient pharmacy and geriatric in-patients respectively. Additional knowledge on antimicrobials use in adult out-patient pharmacy will augment the understanding of antibiotic use in a typical Nigerian tertiary health institution and help develop standards for guidelines for antibiotic use process in teaching hospitals in Africa generally and Nigeria in particular. It is also pertinent that monitoring of outpatient antibiotic prescribing data be done regularly to analyze antibiotic usage data, to better understand trends, identify where interventions to improve prescribing are most needed and to measure progress.

\section{Materials And Methods}

\section{Study area}

This is a retrospective observational study using prescriptions from adult out-patient pharmacy of NAUTH, Nnewi in 2018. The NAUTH is a federal government-owned hospital. The 350-bed hospital renders medical care to patients, being a referral centre for patients in the state and its environs. It is also a 
training centre for medical personnel at all levels and other health personnel. The adult out-patient pharmacy serves the adult out-patient clinics in the hospital. Two major kinds of prescriptions are received in the pharmacy; National Health Insurance Scheme and Drug Revolving funded prescription.

\section{Data Collection Tool}

All the prescription sheets containing one or more antibiotics in the year 2018 were used in the study. The proforma for the data collection contain the following information: Identification code, age, sex, antibiotic prescribed, number of antibiotics per prescription, number of medicines per prescription, dosage form, generic prescribing (yes/no), Drug on Essential Drug List (yes/no) and Cost of the antibiotic(s).

\section{Data Management And Analysis}

Data were evaluated using the WHO-developed prescribing indicators [13] and The Guidelines for Anatomical Therapeutic Chemical (ATC) classification and Defined Daily Dose (DDD) assignment 2019 [14]. The ATC classification system and the DDD as a measuring unit are recommended by the WHO for drug utilization monitoring and research. The WHO indicators calculated included: average number of drugs per encounter, percentage of drugs prescribed from generics, percentage of encounters with an antibiotic prescribed, percentage of encounter with an injection prescribed, and percentage of drugs prescribed from the National Essential Medicine List (EML). The rationality of prescriptions was evaluated by using some of the WHO core drug prescribing indicators, that is, (a) the average number of drugs per encounter, (b) percentage of encounters with an antibiotic, (c) percentage of encounters with an injection, and (d) percentage of drugs prescribed from the essential drugs list or formulary. Descriptive statistics were used to indicate the percentages and averages of the variable. Inferential statistics were also used to arrive at definite conclusions. GraphPad prism 5.0 Software was used for the statistical analysis.

\section{Ethical Consideration}

The study protocol was approved by the Ethics Committee of Nnamdi Azikiwe University Teaching Hospital, Nnewi. Approval number: NAUTH/CS/66/VOL.12/005/2019/002.

\section{Results}

Table 1

Gender distribution in the study prescriptions

\begin{tabular}{|c|c|c|c|c|}
\hline \multirow[t]{2}{*}{ Age (yrs.) } & \multicolumn{3}{|l|}{ Gender } & \multirow[t]{2}{*}{ Total } \\
\hline & Males N (\%) & Females N (\%) & Nil Sex N (\%) & \\
\hline Adult/no specific age & $13(24.07)$ & 39 (72.22) & $2(3.70)$ & 54 \\
\hline $16-20$ & $4(40.00)$ & $6(60.00)$ & $0(0)$ & 10 \\
\hline $21-25$ & 8 (33.33 & $16(66.67)$ & $0(0)$ & 24 \\
\hline $26-30$ & $11(42.31)$ & 15 (57.69) & $0(0)$ & 26 \\
\hline $31-35$ & $1128.95)$ & 27 (71.05) & $0(0)$ & 38 \\
\hline $36-40$ & $13(23.64)$ & $42(76.36)$ & $0(0)$ & 55 \\
\hline $41-45$ & $12(21.43)$ & 43 (76.79) & $1(1.79)$ & 56 \\
\hline $46-50$ & $7(11.48)$ & $54(88.52)$ & $0(0)$ & 61 \\
\hline $51-55$ & $12(27.91)$ & 31 (72.09) & $0(0)$ & 43 \\
\hline $56-60$ & $12(50.00)$ & $12(50.00)$ & $0(0)$ & 24 \\
\hline $61-65$ & $11(52.38)$ & $10(47.62)$ & $0(0)$ & 21 \\
\hline $66-70$ & $5(35.71)$ & $9(64.29)$ & $0(0)$ & 14 \\
\hline $71-75$ & $6(37.50)$ & $10(62.50)$ & $0(0)$ & 16 \\
\hline $76-80$ & $2(50.00)$ & $2(50.00)$ & $0(0)$ & 4 \\
\hline $81-85$ & $1(50.00)$ & $1(50.00)$ & $0(0)$ & 2 \\
\hline $86-90$ & $2(100.00)$ & $0(0)$ & $0(0)$ & 2 \\
\hline TOTAL & $130(29 \%)$ & $317(70 \%)$ & $3(1 \%)$ & $450(100 \%)$ \\
\hline
\end{tabular}

Not all the demographic data (sex, age, weight, and height) were included in the prescriptions assessed. From the result, $<1 \%(4 / 450)$ of the prescription sheets had no specific sex indicated (Fig. 1) while 12\% (54/450) had no specific age indicated in their prescriptions (Fig. 2). Also, the class distribution of the patients' prescriptions showed that the highest number of prescriptions contained patients within the 46-50 age bracket (Fig. 2), followed by $41-45$ and $36-$ 
40 classes respectively. The least class was $86-90$. Chi-square analysis of the gender distribution in the prescriptions showed that there was a significantly higher (P-value $=0.0038)$ females, $317(70 \%)$, compared to males (about two times that of the males (Table 1).

Table 2

Drugs prescribed from Essential Drug list (EDL)

\begin{tabular}{|lllll|}
\hline \multirow{2}{*}{ Gender } & \multicolumn{2}{l}{ Essential Drug List } & \multirow{2}{*}{ Total } \\
\cline { 2 - 4 } & Yes & No & Yes/No & \\
\hline Male & 108 & 18 & 3 & 129 \\
\hline Female & 266 & 36 & 14 & 316 \\
Nil Sex & 5 & 0 & 0 & 5 \\
\hline TOTAL & $\mathbf{3 7 9 ( \mathbf { 8 4 . 2 2 } \% )}$ & $\mathbf{5 4 ( \mathbf { 1 2 } \% )}$ & $\mathbf{1 7 ( 3 . 7 8 \% )}$ & $\mathbf{4 5 0}(\mathbf{1 0 0 \% )}$ \\
\hline
\end{tabular}

Key: Yes = All the drugs in the prescription are from Essential Drug list; $\mathrm{No}=$ All the drugs in the prescription are NOT from Essential Drug list; Yes $/$ No $=$ some of the drugs in the prescription are from Essential Drug list; Nil Sex = Gender not indicated in the prescription.

The Chi-square test of the 450 prescriptions reviewed for trend analysis of essential drug list compliance showed no significant difference $(P$-value $=0.6935)$. A greater percentage (84.22\%) of the prescriptions was from Essential Drug list (Table 2).

Table 3

Antibiotic Use profiling

\begin{tabular}{|c|c|c|c|c|c|c|c|c|c|}
\hline \multicolumn{10}{|c|}{ Antibiotic class and Number of times prescribed (\%) } \\
\hline $\begin{array}{l}\text { Age } \\
\text { (yrs.) }\end{array}$ & $\begin{array}{l}\text { Amino- } \\
\text { penicillin }\end{array}$ & Cephalosporin & Nitroimidazoles & Fluoroquinolones & Sulphonamide & Macrolide & Penicillins & Tetracyclines & Lincosamide \\
\hline $\begin{array}{l}\text { Nil } \\
\text { specific } \\
\text { age }\end{array}$ & 17 & 8 & 12 & 18 & 0 & 9 & 0 & 8 & 0 \\
\hline $16-20$ & 5 & 2 & 2 & 1 & 0 & 3 & 0 & 1 & 0 \\
\hline $21-25$ & 13 & 2 & 13 & 3 & 0 & 3 & 0 & 2 & 0 \\
\hline $26-30$ & 14 & 8 & 5 & 5 & 1 & 5 & 0 & 2 & 0 \\
\hline $31-35$ & 22 & 5 & 12 & 6 & 1 & 4 & 0 & 0 & 0 \\
\hline $36-40$ & 32 & 7 & 8 & 13 & 1 & 10 & 0 & 1 & 0 \\
\hline $41-45$ & 32 & 5 & 9 & 11 & 1 & 15 & 0 & 1 & 0 \\
\hline $46-50$ & 40 & 5 & 12 & 9 & 0 & 17 & 2 & 1 & 0 \\
\hline $51-55$ & 20 & 6 & 11 & 11 & 2 & 2 & 1 & 1 & 0 \\
\hline $56-60$ & 13 & 1 & 11 & 8 & 0 & 4 & 0 & 1 & 0 \\
\hline $61-65$ & 4 & 1 & 6 & 11 & 0 & 4 & 1 & 1 & 0 \\
\hline $66-70$ & 4 & 6 & 3 & 5 & 0 & 0 & 0 & 0 & 1 \\
\hline $71-75$ & 11 & 1 & 2 & 3 & 0 & 5 & 0 & 0 & 0 \\
\hline $76-80$ & 2 & 0 & 2 & 2 & 0 & 0 & 0 & 0 & 1 \\
\hline $81-85$ & 0 & 0 & 2 & 0 & 0 & 0 & 0 & 0 & 0 \\
\hline $86-90$ & 1 & 0 & 1 & 0 & 0 & 1 & 0 & 0 & 0 \\
\hline $\begin{array}{l}\text { TOTAL } \\
\text { (617) }\end{array}$ & 230 & 57 & 111 & 106 & 6 & 82 & 4 & 19 & 2 \\
\hline
\end{tabular}

Two-Way ANOVA of Antibiotic Use Profile (Table 3) showed that antibiotic selection by class was significantly different and accounted for $44.02 \%$ of the total variance seen in the selection practice/prescription pattern ( $P$ value is $<0.0001)$. From the result, Amino-penicillin $(230)$ the most prescribed class of antibiotic in the year in review, followed by Nitroimidazoles (111) and fluoroquinolone (106), the least prescribed antibiotic was Lincosamides (2) (Fig. 2) Also, the age of participants accounted for $19.48 \%$ of the total variance seen in the selection practice and so, age significantly affected the selection practice/prescription pattern with a P-value is $<0.0001$. 
Table 4

Distribution of dosage forms of prescribed antibiotics.

\begin{tabular}{|lllll|}
\hline Age (yrs.) & Oral N (\%) & Parenteral N (\%) & Other forms N (\%) & TOTAL \\
\hline AD & $54(100)$ & $0(0.00)$ & $0(0.00)$ & 54 \\
\hline $16-20$ & $10(90.91)$ & $1(9.09)$ & $0(0.00)$ & 11 \\
\hline $21-25$ & $23(95.83)$ & $0(0.00)$ & $1(4.17)$ & 24 \\
\hline $26-30$ & $25(92.59)$ & $1(3.70)$ & $1(3.70)$ & 27 \\
\hline $31-35$ & $38(97.44)$ & $1(2.56)$ & $0(0.00)$ & 39 \\
\hline $36-40$ & $52(94.55)$ & $2(3.64)$ & $1(1.82)$ & 55 \\
\hline $41-45$ & $54(98.18)$ & $0(0.00)$ & $2(1.82)$ & 55 \\
\hline $46-50$ & $61(98.39)$ & $1(1.61)$ & $0(0.00)$ & 62 \\
\hline $51-55$ & $40(93.02)$ & $2(4.65)$ & $1(2.33)$ & 43 \\
\hline $56-60$ & $17(100)$ & $0(0.00)$ & $0(0.00)$ & 17 \\
\hline $61-65$ & $20(100)$ & $0(0.00)$ & $0(0.00)$ & 20 \\
\hline $66-70$ & $10(100)$ & $0(0.00)$ & $0(0.00)$ & 10 \\
\hline $71-75$ & $12(100)$ & $0(0.00)$ & $0(0.00)$ & 12 \\
\hline $76-80$ & $1(100)$ & $0(0.00)$ & $0(0.00)$ & 1 \\
\hline $81-85$ & $1(100)$ & $0(0.00)$ & $0(0.00)$ & 1 \\
\hline $86-90$ & $2(100)$ & $0(0.00)$ & $0(0.00)$ & 2 \\
\hline T0TAL & $420(97.00)$ & $8(1.85)$ & $5(1.15)$ & 433 \\
\hline
\end{tabular}

One-Way ANOVA of Table 4 (Dosage forms profile) showed that the oral dosage forms with a percent value $97 \%$ were significantly more prescribed ( $P$-value < 0.0001 ) compared with any other dosage form encountered in the study. There was no significant difference in the prescription patterns of parenteral and other dosage forms (P-value $>0.05)$.

Table 5

Cost analysis of the antibiotic prescriptions

\begin{tabular}{|lllllll|}
\hline ITEMS & & \multicolumn{5}{c|}{ COST FACTOR (\$) } \\
\hline $\begin{array}{l}\text { Number of } \\
\text { antibiotics per } \\
\text { prescription }\end{array}$ & $\begin{array}{l}\text { Prescriptions } \\
\text { with } \\
\text { antibiotics }\end{array}$ & $\begin{array}{l}\text { Mean number of } \\
\text { drugs per } \\
\text { prescription }\end{array}$ & $\begin{array}{l}\text { Sum of items } \\
\text { per prescription }\end{array}$ & $\begin{array}{l}\text { Antibiotics } \\
\text { Cost (Total) }\end{array}$ & $\begin{array}{l}\text { Antibiotics } \\
\text { cost } \\
\text { (Mean) }\end{array}$ & $\begin{array}{l}\text { The total cost of } \\
\text { items in the } \\
\text { prescription }\end{array}$ \\
\hline One & 296 & $4.28 \pm 1.69$ & 1,268 & $1,482.283$ & 2.66172 & $3,175.19191$ \\
Two & 132 & $4.46 \pm 1.69$ & 618 & $2,964.56588$ & 6.57331 & $1,043.7215$ \\
Three & 22 & $5.55 \pm 1.69$ & 122 & 139.974 & 6.36419 & 237.4882 \\
\hline
\end{tabular}

The result of the Cost analysis of antibiotics prescriptions (Table 5), showed that average cost of items (prescriptions) with two antibiotics was the highest with the value of 14.0807 dollars, followed by prescriptions with three antibiotics (14.0807 dollars), and then prescriptions with one antibiotic (6.39858 dollars). Also, from the result, there were more prescriptions with only one antibiotic (65.78\%), followed by prescriptions with two antibiotics (29.33\%), and then prescriptions with three antibiotics (4.89\%) (Fig. 3).

\section{Discussion}

The demographic profile showed that out of the 451 prescriptions that had antibiotics, higher number of females (70.44\%) than males (28.89\%) utilized antibiotics. This is similar to an earlier report ${ }^{4}$ but varies to another studies ${ }^{7,15}$. The probable reasons for the more females than males utilizing antibiotics, as seen in our study may be due to the sociological factors or that the female population was more exposed to environmental influences such that they get more infectious diseases [15]. Patients in the age group of 36-40 years (10\%) for males and $46-50$ years (17.03\%) for females were prescribed maximum antibiotics and patients in the age group of $81-85$ years $(0.769 \%)$ for males and $86-90$ years $(0 \%)$ were prescribed the least amount of antibiotics. Generally, the age group, $46-50$ had the highest antibiotic prescriptions across the both gender (13.56\%), followed by the $41-45$ (12.44\%).

Irrational use of antibiotics is a significant contributor to the development of antibiotic resistance [16]. Antibiotic resistance has posed a significant threat to the management of infectious diseases and the incidence of antibiotic resistance is increasing day by day. Urgent steps are needed to promote the rational use of antibiotics. Antibiotics utilization study can help in fostering the habits of rational use of antibiotics which means at the right dose, for the right duration, and at the right cost. Antibiotics are an important category of drugs and its improper use can result in antibiotic resistance. One of the causes of resistance against antibiotics is the high number of antibiotics prescribed for patients per encounter [4]. The average number of drugs per prescription is an 
important parameter while doing a prescription audit. Multiple drug prescribing results in poly-pharmacy; this may attribute to irrational prescribing and adverse effects. In this study, the average number of antibiotics per prescription was 1.26 same to the study organized in a hospital in Guwahati [17]. Some other studies have reported an average number of antibiotics per the prescription of $1.83,1.8$ and 1.6 respectively $[18,19,20]$. Also, it was found that even though the number of prescriptions with one antibiotics was higher than that with two, and then with three, the average number of drugs per prescription that had one antibiotic was 4.28 , with two antibiotics was 4.46 , and that which had three antibiotics was 5.55 , which is more than double the average number (i.e., 2) recommended by WHO and in several countries (Indonesia, Niger, Nigeria, India, Ghana, and Pakistan) the prescriptions were for three or more drugs [21].

Essential medicine list or formulary issued to measure the degree to which practices conform to national drug policy, as indicated by prescribing from the national essential medicines list or formulary for the type of facility surveyed. A total number of 617 antibiotics were prescribed in 450 prescriptions. As per WHO drug use indicators, out of the total antibiotics prescribed, 379 (84.22\%) were from the Nigerian Essential Medicines List. The most common antibiotics prescribed were Amino-penicillins (37.28\%) mainly coamoxiclav 625 mg followed by Nitroimidazoles (17.99\%) mostly metronidazole, Fluoroquinolones (17.18\%) mostly ciprofloxacin, Macrolides (13.29\%), Cephalosporins (9.24\%), Tetracyclines (3.08\%), and Lincosamides (0.32\%). This is similar to an earlier report by Yimenu et al, who observed prescribed antibiotic in this sequence: Penicillin $>$ Macrolid $>$ Fluoroquinolons $>$ Cephalosporin $>$ Tetracyclines [4]. Aminopenicillins are bactericidal beta-lactam antibiotics. They are effective against most gram-positive bacteria and are clinically used in treating upper and lower respiratory tract infections, endocarditis urinary tract infection and others. Similarly an earlier report [4] indicates that most antibiotics prescriptions in the adult outpatient unit are against medical conditions as listed. Essential medicine lists have been shown to improve the quality and cost-effectiveness of health care delivery when combined with proper procurement policies and good prescribing practices. Adequately, in this study, most of the antibiotics were prescribed from the essential medicines list.

The percentage of encounter with injections prescribed was very less than the ideal value of World Health Organization (13.4\% - $24.1 \%)$ where it was found to be $1.8 \%$. Most of the prescriptions were in oral dosage forms. This may be due to patient visits in the out-patient department, General out-patient department (GOPD) only at a less severe stage where extra care is not needed. The less use of injection leads to decreased cost of medication, less tissue necrosis, less anaphylactic shock, reduces chances of transmission of blood-borne diseases, including HIV [22]. A similar result was obtained by Yimenu et a/ while assessing the antibiotic prescribing patterns using World Health Organization prescribing indicators at the outpatient Pharmacy Department of University of Gondar referral hospital, Gondar, Northwest Ethiopia, reported that majority of antibiotics were prescribed by oral route $(476,84 \%)$ followed by the parenteral route $(39,4 \%)$, as observed in this study [4].

\section{Conclusion}

Though the percentage of drugs prescribed from the essential medicines list was found to be satisfactory, the findings of this study revealed that drug utilization pattern was not optimal following the standard values of WHO prescribing indicators. This study highlights the need to minimize the average number of drugs per prescription, the percentage of antibiotics, and also to minimize the percentage of injection. Therefore, a strict protocol for prescribers is required to promote rational use of antibiotics which would not only prevent antibiotic resistance but also reduce the treatment expenditure. Though the appropriateness of the antibiotics prescribed was not evaluated, the need for the introduction of guidelines for prescribing antibiotics and the role of Hospital Antibiotic Policy must be made mandatory with implementation.

\section{Declarations}

\section{Declarations}

\section{Acknowledgements}

The authors are grateful to all the community pharmacists and the entire staff of Adult Out-patient Pharmacy of Nnamdi Azikiwe University Teaching Hospital (NAUTH), Nnewi for their professional assistance and participation in the survey.

\section{Conflict of interest}

Nwanneka Onyeaso is a staff of NAUTH while Oli Angus and Ofomata Chijioke are staff of Nnamdi Azikiwe University, the University to which NAUTH is affiliated. Other authors declare no conflicts of interest.

\section{Authors' contributions}

Angus N. OLI conceptualized the study and did statistical analysis; Nwanneka ONYEASO conducted the study and did data collection; Stephen EMENCHETA drafted the manuscript; Chijioke M. OFOMATA and James-Paul KRETCHY revised the manuscript for intellectual content while Augustine OKHAMAFE designed and supervised the study.

\section{Funding}

This research received no specific grant from any funding agency in the public, commercial, or not-for-profit sectors.

\section{References}

1. Hashemi S, Nasrollah A, Rajabi M. Irrational antibiotic prescribing: a local issue or global concern? EXCLI J. 2013;12:384-95. 
2. Ofori-Asenso R, Agyeman AA. Irrational Use of Medicines-A Summary of Key Concepts. Pharmacy (Basel Switzerland). 2016;4(4):35. https://doi.org/10.3390/pharmacy4040035.

3. $10.3389 /$ fmicb. 2016.01860

Tiong JJ, Loo JS, Mai CW. (2016). Global Antimicrobial Stewardship: A Closer Look at the Formidable Implementation Challenges. Frontiers in Microbiology. 2016; 7: 1860. https://doi.org/10.3389/fmicb.2016.01860.

4. Yimenu DK, Emam A, Elemineh E, Atalay W. Assessment of Antibiotic Prescribing. Patterns at Outpatient Pharmacy Using World Health Organization Prescribing Indicators. Journal of Primary Care Community Health. 2019;10:1-8. https://doi.org/10.1177/2150132719886942.

5. Sisay M, Mengisu G, Molla B, Amare F, Gabriel T. Evaluation of rational drug use based on World Health Organization core drug use indicators in selected public hospitals of eastern Ethiopia: a cross sectional study. BMC Health Serv Res. 2017;17:161. https://doi.org/10.1186/s12913-017-2097-3.

6. Pipalova R, Vice J, Matoulkova P. The evaluation of antibiotic prescribing in general practice using a health insurance company database: penicillin's use. Croat Med J. 2012;53:505-6.

7. Kanishk K, Rupinder KS, Upendra KJ. Drug Utilization Evaluation of Antibiotics in DhUttarakashi. IOSR Journal of Pharmacy. 2017;7(9):(II): 1-5.

8. Oli AN, Itumo CJ, Okam PC, Ezebialu IU, Okeke KN, Ifezulike CC, Ezeobi I, Emechebe GO, Okezie UM, Adejumo SA, Okoyeh JN. Carbapenem-Resistant Enterobacteriaceae Posing a Dilemma in Effective Healthcare Delivery. Antibiotics (Basel). 2019; 8(4). http://dx.doi.org/10.3390/antibiotics8040156. PubMed PMID: 31547023.

9. Yenet W. Base line survey on drug prescribing indicators for outpatients in Jimma University specialized hospital, South West Ethiopia. Eth J Health Sci. 2005;15(2):147-55.

10. Adje DU, Oli AN. Community Pharmacy in Warri, Nigeria - A Survey of Practice Details;Sch. Acad J Pharm. 2013;2(5):391-7. http://saspublisher.com/wpcontent/uploads/2013/10/SAJP25391-397.pdf.

11. Nduka SO, Edebeatu C, Isidienu CP, Amorha KC. Prescribing practices for pediatric out-patients: A case study of two teaching hospitals in Nigeria. Tropical Journal of Pharmaceutical Research. 2017;16(3):705. http://dx.doi.org/10.4314/tjpr.v16i3.28.

12. Osemeke N, Hart O, Cosmas N, Ohumagho I. Geriatric Prescription in a Nigerian Tertiary Hospital. Journal of Basic Clinical Pharmacy. 2017;8(1):20. http://dx.doi.org/10.4103/0976-0105.195086.

13. World Health Organization. Introduction to Drug Utilization Research. http://apps.who.int/medicinedocs/en/d/Js4876e/2.2.html. 2003. Accessed on 3rd February 2019.

14. WHO Collaborating Centre for Drug Statistics Methodology. Guidelines for ATC classification and DDD assignment 2019. Norway: Oslo; 2018. https://www.whocc.no/filearchive/publications/2019_guidelines_web.pdf. Accessed on 8th February 2019.

15. Khan Z, Ahmed N, Rehman A, Khan FU, Karatas Y. Utilization pattern of antibiotics and patient care indicators in the teaching hospitals, Islamabad, Pakistan. SN Comprehensive Clinical Medicine. 2019;1:812-6. https://doi.org/10.1007/s42399-00131-z.

16. Odonkor S, Addo K. Bacteria Resistance to Antibiotics: Recent Trends and Challenges. International Journal of Biological \& Medical Research. 2011; 1204-1210.

17. Singha J, Chowdhury D, Hazarika H, Krishnatreyya H. Drug utilization studies on antibiotics in the department of medicine (in patient) of gauhati medical college \& hospital (gmch), Guwahati. International Journal of Pharmacy Practice Drug Research. 2018;8:34-9. http://dx.doi.org/10.21276/ijppdr.2018.8.1.7.

18. Meher BR, Mukherjee D, \&Udayshankar. A study on antibiotic utilization pattern in a general medicine ward of a tertiary care teaching hospital. Journal of Chemical \& Pharmaceutical Research; 2014; 6(7): 1847-1849.

19. RemeshA, Retnavally K, Salim S, Gayathri A, Nair U. Antibiotics prescribing pattern in the in-patient departments of a tertiary care hospital. Archives of Pharmacy Practice. 2013;4(2):71. http://dx.doi.org/10.4103/2045-080x.112987.

20. 10.1186/1471-2482-11-20

Harlaar JJ, Deerenberg EB, van Ramshorst GH, Lont HE, van der Borst EC, Schouten WR, et al. A multicenter randomized controlled trial evaluating the effect of small stitches on the incidence of incisional hernia in midline incisions. BMC Surgery. Springer Science and Business Media LLC; 201;11(1). http://dx.doi.org/10.1186/1471-2482-11-20.

21. Isah AO, Ross-Degnan D, Quick J, Laing R, Mabadeje AFB. The development of standard values for the WHO drug use prescribing indicators. ICUM/EDM/WHO.http://archives.who.int/prduc2004/rducd/ICIUM_Posters/1a2_txt.htm.

22. Geetha P, Vijayalakshmi P, Tilak S, Maheswaran A, Naray N. Prescription analysis to evaluate the rational use of drugs by using who health care indicators. International Journal of Multidisciplinary Research Development. 2015;2(5):358-60.

\section{Figures}




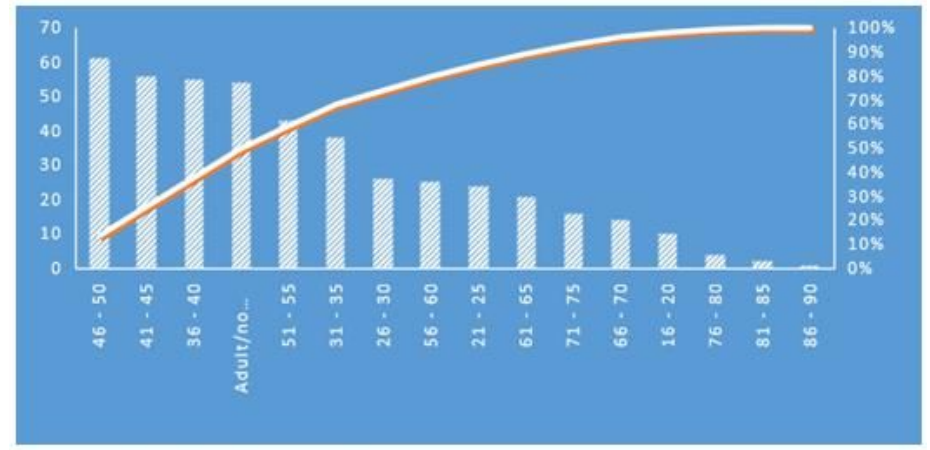

Fig. 1 Class distribution of antibiotic usage.

\section{Figure 1}

Class distribution of antibiotic usage

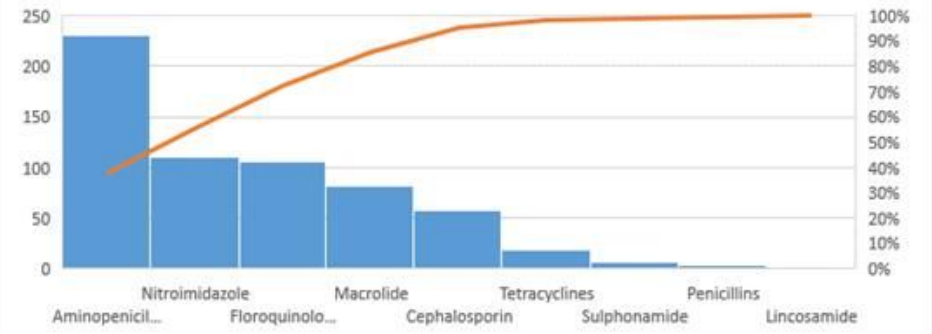

Fig. 2 Graph of antibiotic utilization.

Figure 2

Graph antibiotic utilization

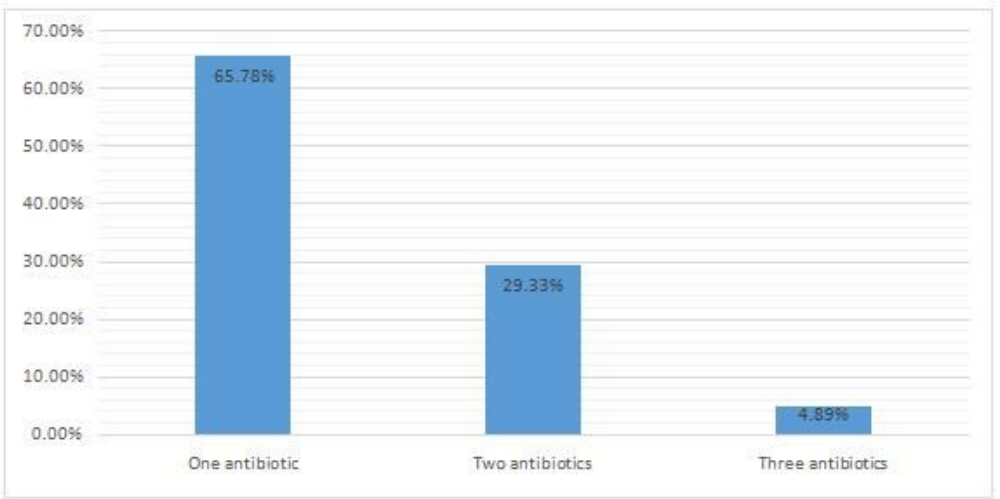

Fig. 3 Percentage of the number of antibiotics prescribed per encounter.

Figure 3

Percentage of the number of antibiotic prescribed enounter.

\section{Supplementary Files}

This is a list of supplementary files associated with this preprint. Click to download.

- OlietalEvaluationofoneyearantibioticsutilization.pdf 